\title{
CXCR7 functions in colon cancer cell survival and migration
}

\author{
HONGXIAN WANG ${ }^{1}$, LINYU TAO $^{1}$, KE QI $^{1}$, HAOYUN ZHANG $^{1}$, DUO FENG $^{1}$, WENJUN WEI ${ }^{1}$, \\ HENG KONG ${ }^{1}$, TIANWEN CHEN ${ }^{1}$, QIUSHENG LIN ${ }^{1}$ and DAOJIN CHEN ${ }^{2}$ \\ ${ }^{1}$ Department of Surgery, Affiliated Nanshan Hospital, Guangdong Medical College, Shenzhen, Guangdong 518052; \\ ${ }^{2}$ Department of Surgery, The Third Xiangya Hospital of Central South University, Changsha, Hunan 410083, P.R. China
}

Received April 30,2015; Accepted August 3, 2015

DOI: $10.3892 /$ etm.2015.2748

\begin{abstract}
C-X-C chemokine receptor 7 (CXCR7) is a known promoter of tumor progression and metastasis; however, little is known about its role in colon cancer. The aim of the present study was to investigate the function of CXCR7 in human colon cancer cells. CXCR7 mRNA levels were examined in HT-29 and SW-480 human colon cancer cell lines using a quantitative polymerase chain reaction. CXCR7-knockdown was performed with small interfering RNA and lentiviral-mediated gene delivery. Immunofluorescence (IF) was conducted to examine CXCR7 expression and localization in colon cancer cells. Cell survival and migration were evaluated using MTT and migration assays, respectively. HT-29 cells expressed higher levels of CXCR7 mRNA and were therefore used in subsequent experiments. IF staining revealed that the CXCR7 protein was expressed on the cell membrane, and its expression decreased following CXCR7-short hairpin RNA lentiviral transfection. Lentiviral CXCR7-knockdown resulted in decreased cell survival and migration; however, MTT assays revealed that the lentiviral vector itself was cytotoxic. This cytotoxicity was indicated as the cell survival of the negative control group cells was significantly decreased compared with that of the blank control group cells $(\mathrm{P}<0.05)$. In conclusion, it is becoming increasingly evident that $\mathrm{CXCR} 7$ plays a role in colon cancer promotion, suggesting that CXCR7 is a promising biomarker for chemokine receptor-based drug development. Furthermore, the fact that CXCR7 is expressed on the membrane and not intracellularly makes it a prime target for drug-based intervention.
\end{abstract}

\section{Introduction}

$\mathrm{C}-\mathrm{X}-\mathrm{C}$ chemokine receptor 4 (CXCR4) is an exclusive receptor for stromal cell-derived factor-1 (SDF-1, also known as CXCL12) that has been widely recognized to function in

Correspondence to: Dr Daojin Chen, Department of Surgery, The Third Xiangya Hospital of Central South University, 138 Tongzipo Road, Changsha, Hunan 410083, P.R. China

E-mail: hnsmx001@outlook.com

Key words: colon cancer, C-X-C chemokine receptor 7, lentiviral vector, RNA interference tumor progression. The orphan receptor CXCR7 has been identified as another high-affinity CXCL12 receptor that can also bind CXCL11 (1-3). The biological effects of CXCR4 may, therefore, be attributed to CXCR7 (4).

CXCR7 is an atypical, chemokine-specific seven-transmembrane guanosine-binding protein-coupled receptor that, unlike other CXCRs, does not induce intracellular $\mathrm{Ca}^{2+}$ release following ligand binding $(1,5)$. Previous characterization of CXCR7-deficient mice has suggested that the receptor plays an innate role in fetal cardiac development and B-cell localization (1,6-8). In addition, studies have indicated that, like CXCR4, CXCR7 is weakly expressed or absent in the majority of normal tissues but is highly expressed in several types of cancer, including prostate, lung, liver, melanoma, rhabdosarcoma, brain, breast and pancreas $(1,7,9)$. Furthermore, CXCR7 expression is necessary for cancer cell survival, tumor development and metastases $(1,7,9)$.

Little is currently known about the role of CXCR7 in colon cancer growth and metastasis. The aim of the present study was to investigate the localization of CXCR7 in human colon cancer cell lines and to explore its function in cell survival and migration by reducing its expression using a CXCR7-small interfering RNA (siRNA) recombinant lentivirus.

\section{Materials and methods}

\section{Screening of cell lines}

Cell culture. The HT-29 and SW-480 human colon cancer cell lines (Cell Center of Xiangya Medical College of Central South University, Changsha, China) were cultured in RPMI-1640 medium (Gibco ${ }^{\mathrm{TM}}$; Life Technologies, Carlsbad, CA, USA) supplemented with $10 \%$ fetal bovine serum (Gibco), $100 \mathrm{U} / \mathrm{ml}$ penicillin and $100 \mu \mathrm{g} / \mathrm{ml}$ streptomycin. Cells were maintained at $37^{\circ} \mathrm{C}$ in an incubator with $5 \% \mathrm{CO}_{2}$ and saturated humidity.

Quantitative polymerase chain reaction ( $q P C R$ ) of CXCR7 $m R N A$. Total RNA was extracted from HT-29 and SW-480 cells in the logarithmic growth phase using TRIzol ${ }^{\circledR}$ according to the manufacturer's instructions (Invitrogen ${ }^{\mathrm{TM}}$; Life Technologies, Paisley, UK). cDNA was synthesized using a RevertAid ${ }^{\mathrm{TM}}$ kit (MBI Fermentas, Vilnius, Lithuania). Fluorescence qPCR was performed in a $25-\mu 1$ reaction mixture containing $12.5 \mu \mathrm{l}$ $\mathrm{SYBR}^{\circledR}$ Premix Ex Taq ${ }^{\mathrm{TM}}$ (Takara Bio, Otsu, Japan) (2X), $1 \mu \mathrm{l} 10 \mu \mathrm{M}$ primer pair mixture, $2 \mu \mathrm{l}$ cDNA template and double-distilled $\mathrm{H}_{2} \mathrm{O}$. Amplification was initiated by predegeneration at $95^{\circ} \mathrm{C}$ for $5 \mathrm{~min}$, followed by 40 cycles of denaturation 
at $94^{\circ} \mathrm{C}$ for $20 \mathrm{sec}$, annealing at $53^{\circ} \mathrm{C}$ for $20 \mathrm{sec}$ and extension at $72^{\circ} \mathrm{C}$ for $20 \mathrm{sec}$, with a final extension at $72^{\circ} \mathrm{C}$ for $5 \mathrm{~min}$. The CXCR7 primer sequences were as follows: Forward, 5'-ctgcgtccaacaatgag-3' and reverse, 5'-ggaagtagaagacagcga ta-3' (Telebio Biomedical Co., Ltd., Shanghai, China). 18S rRNA was used as an internal normalized reference (forward, 5'-acggacaggattgacagatt-3'; reverse, 5'-gccacttgtccctctaag aa-3'). CXCR7 gene expression was analyzed using the $\Delta \Delta \mathrm{Ct}$ method, as follows: $2^{-\Delta \Delta \mathrm{CT}}[\Delta \Delta \mathrm{CT}=(\mathrm{Ct}(\mathrm{CXCR} 7)-\mathrm{Ct}(18 \mathrm{~S}$ rRNA $\left.))_{\text {target }}-(\mathrm{Ct}(\mathrm{CXCR} 7)-\mathrm{Ct}(18 \mathrm{~S} \text { rRNA }))_{\text {internal standard }}\right]$. The cell line with the highest CXCR7 expression was used for all subsequent experiments.

Construction of recombinant CXCR7-short hairpin RNA lentiviral vector ( $L V-C X C R 7-s h R N A)$. LV-CXCR7-shRNA was constructed as previously described (10). The small interfering RNA (siRNA) sequence against CXCR7 (GenBank, NM_020311) was designed using BLOCK-iT ${ }^{\text {TM }}$ RNAi Designer (https://rnaidesigner.invitrogen.com/rnaiexpress/design.do) as follows: gcagccggaagatcatcttct.Double-strandedCXCR7-shRNA hairpins (forward, 5'-accacgcgtggcagccggaagatcatcttctctctcttg aattc-3'; reverse, 5'-aaaatcgataaaaaagcagccggaagatcatcttctgaa ttcaagagag-3') were synthesized and cloned into the plVTHM shuttle plasmid (Telebio Biomedical Co., Ltd., Shanghai, China) with T4 DNA ligase (New England Biolabs, Ipswich, MA, USA). 293T cells (Cell Bank of the Shanghai Institutes for Biological Sciences, Shanghai, China) were co-transfected with plVTHM-CXCR7-shRNA and lentiviral packaging plasmids. The viral supernatant was collected $72 \mathrm{~h}$ after transfection. The negative control was simultaneously generated, and the standard negative control recombinant plasmid (interference sequence: ttctccgaacgtgtcacgt) was provided by Telebio Biomedical Co., Ltd.

Transfection. The human colon cancer cells were divided into three groups: Experimental (treated with LV-CXCR7-shRNA), negative control (treated with LV-shRNA negative control) and blank control (no treatment). Each group of cells was inoculated in six-well culture plates and incubated overnight prior to transfection. As the cells reached $60-75 \%$ confluence, CXCR7 shRNA or negative control virus vectors were inoculated [multiplicity of infection $(\mathrm{MOI})=$ virus number/cell number $=20]$. The medium was changed after $24 \mathrm{~h}$ to remove any remaining viral vector. Cells were cultured for $72 \mathrm{~h}$, and green fluorescent protein (GFP) expression was examined using fluorescence microscopy (BA410; Motic, Xiamen, China).

Immunofluorescence (IF) analysis of CXCR7 protein. Cells were seeded and grown on coverslips in six-well culture plates for $24 \mathrm{~h}$ and fixed in a mixture of 6 parts absolute ethanol:3 parts chloroform: 1 part glacial acetic acid for $20 \mathrm{~min}$. The cells were then washed three times in phosphate-buffered saline $(0.01 \mathrm{M}$, $\mathrm{pH}$ 7.2) and blocked with goat serum albumin for $20 \mathrm{~min}$. The coverslips were incubated with primary polyclonal rabbit anti-CXCR7 antibody (1:50; ab12870; Abcam, Cambridge, $\mathrm{UK}$ ) overnight at $4^{\circ} \mathrm{C}$, and then incubated with goat anti-rabbit IgG fluorescein isothiocyanate (FITC)-conjugated secondary antibody (ZF-0311; ZSGB-Bio, Beijing, China) at $37^{\circ} \mathrm{C}$ for $40 \mathrm{~min}$. IF images were visualized using a fluorescence microscope (BA410; Motic).

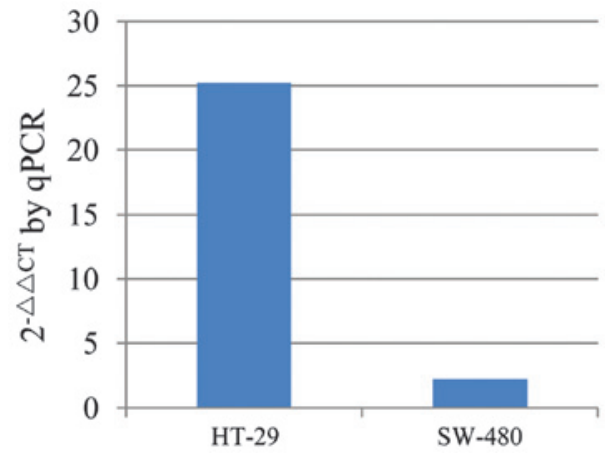

Figure 1. qPCR analysis of C-X-C chemokine receptor 7 mRNA expression in HT-29 and SW-480 cells. qPCR, quantitative polymerase chain reaction.

MTT assay. Each group of cells was seeded in 96-well plates at a density of $\sim 1 \times 10^{4}$ cells $(100 \mu \mathrm{l})$ per well $76 \mathrm{~h}$ after transfection. After 1, 2, 3, 4 and 5 days, MTT (Sigma, St. Louis, MO, USA) was added to the cultures at a final concentration of $0.2 \mathrm{mg} / \mathrm{ml}$ and incubated for $4 \mathrm{~h}$ at $37^{\circ} \mathrm{C}$. Dimethylsulfoxide (Sigma) $(150 \mu \mathrm{l} /$ well) was added to each well following the removal of the supernatant. The optical density (OD) was measured at $490 \mathrm{~nm}$ using a spectrophotometer. Cell survival rates (CSRs) were calculated according to the following formula: $\mathrm{CSR}(\%)=\left(\mathrm{OD}_{\text {dosing cell }} / \mathrm{OD}_{\text {blank control cell }}\right) \times 100$.

Cell migration assay. A $200-\mu 1$ cell suspension containing $1 \times 10^{4}$ cells was seeded into the upper chamber of a Transwell ${ }^{\circledR}$ system $(6.5-\mathrm{mm}$ Transwell filter with $8.0-\mu \mathrm{m}$ pore polycarbonate membrane), and $500 \mu \mathrm{l}$ chemotactic factor from NIH/3T3 cell supernatant (Cell Bank of the Shanghai Institutes for Biological Sciences) was added to the lower chamber. Following incubation at $37^{\circ} \mathrm{C}$ for $24 \mathrm{~h}$, cells that had migrated to the external surface of the membrane were fixed with $4 \%$ paraformaldehyde and stained with hematoxylin and eosin.

Statistical analysis. Statistical analysis was performed using SPSS 19.0 statistical software (IBM SPSS, Armonk, NY, USA). The data are presented as the mean \pm standard deviation. Differences among multiple groups were analyzed using one-way analysis of variance. The differences between two groups were determined using the Student-Newman-Keuls method. $\mathrm{P}<0.05$ was considered to indicate a statistically significant difference.

\section{Results}

CXCR7 mRNA expression in HT-29 and SW-480 human colon cancer cell lines. CXCR7mRNA expression was evaluated in HT-29 and SW-480 cells using qPCR (Fig. 1). The results indicated that CXCR7 mRNA was expressed in both cell lines, although the expression in the HT-29 cells was notably higher than that in the SW-480 cells. HT-29 cells were therefore used for further analysis.

Transfection efficiency of lentiviral vector. HT-29 cells were transfected with LV-CXCR7-shRNA and LV-shRNA negative control, according to the grouping, for $96 \mathrm{~h}(\mathrm{MOI}=20)$, and GFP expression was examined using fluorescence microscopy. 
Table I. Cell survival rates.

\begin{tabular}{lccccc}
\hline Group & Day 1 $(\%)$ & Day 2 $(\%)$ & Day 3 $(\%)$ & Day 4 $(\%)$ & Day 5 (\%) \\
\hline Experimental group $^{\mathrm{a}}$ & $74.16 \pm 1.63$ & $72.97 \pm 3.05$ & $62.01 \pm 4.78$ & $73.23 \pm 4.71$ & $80.78 \pm 7.54$ \\
Negative control group $^{\mathrm{b}}$ & $93.06 \pm 1.30$ & $91.14 \pm 6.22$ & $90.12 \pm 5.47$ & $94.08 \pm 6.87$ & $96.35 \pm 4.16$ \\
Blank control group & 100 & 100 & 100 & 100 & 100 \\
\hline
\end{tabular}

Results are presented as the mean \pm standard deviation. ${ }^{\mathrm{a}} \mathrm{P}<0.05$ vs. the negative control and blank control groups; ${ }^{\mathrm{b}} \mathrm{P}<0.05$ vs. the blank control group.
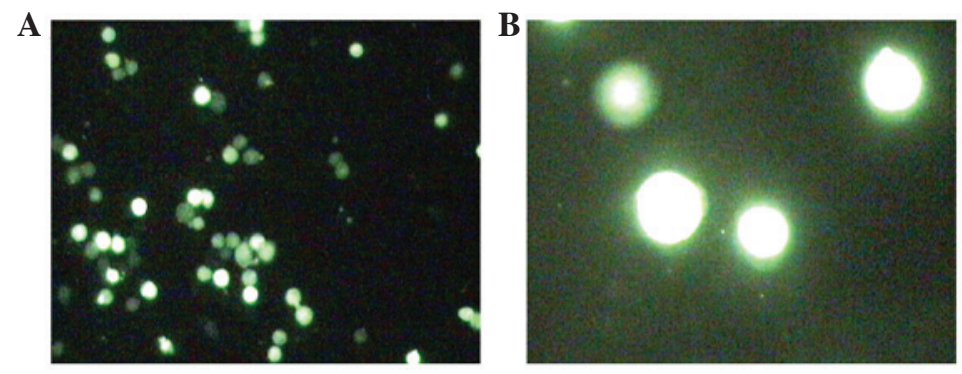

Figure 2. Lentiviral transfection efficiency in HT-29 cells, as assessed using fluorescence microscopy: (A) Magnification, x100; (B) magnification, x400.
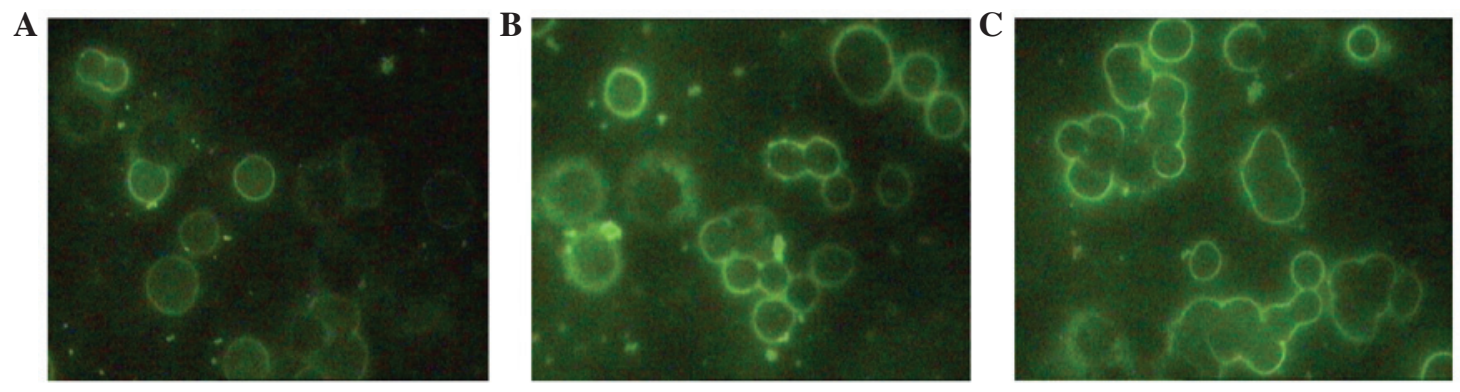

Figure 3. Immunofluorescence analysis of C-X-C chemokine receptor 7 protein in HT-29 cells (magnification, $\mathrm{x} 400$ ). (A) Experimental group; (B) negative control group; (C) blank control group.

An intense green signal (Fig. 2) was observed in $\sim 80 \%$ of the cells. These results showed that the cells could be stably transfected with high efficiency.

CXCR7 protein localizes to the plasma membrane. The localization of CXCR7 protein was examined using IF, and it was found that the protein localized to the membrane and was not intracellular (Fig. 3). CXCR7-knockdown was confirmed to decrease protein expression, as the experimental group of cells showed little to weak expression whereas both the negative control and the blank control group cells showed abundant, intense expression. No obvious differences could be detected between the negative control and blank control groups. The IF analysis suggested that LV-CXCR7-shRNA effectively decreased the expression of CXCR7 protein in HT-29 cells.

CXCR7-knockdown decreases cell survival. Cell survival following CXCR7-knockdown was measured using an MTT assay. As shown in Table I and Fig. 4, the CSRs of cells with knocked down CXCR7 were significantly decreased and the survival curve was lower than that in the negative control

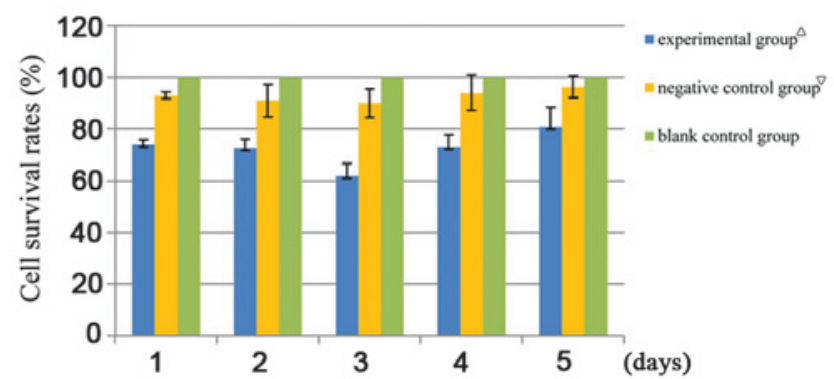

Figure 4. Effect of C-X-C chemokine receptor 7-silencing on cell survival. ${ }^{\Delta} \mathrm{P}<0.05$ vs. the negative control and blank control groups; ${ }^{\nabla} \mathrm{P}<0.05$ vs. the blank control group.

and blank control groups $(\mathrm{P}<0.05)$. The results suggested that CXCR7 inhibition significantly reduced the colon cancer CSR; however, the cell survival of the negative control group cells was also significantly decreased compared with that of the blank control group cells (Table I and Fig. 4, P<0.05). Furthermore, cells in both the experimental and the negative control group showed decreased survival for the first 3 days 

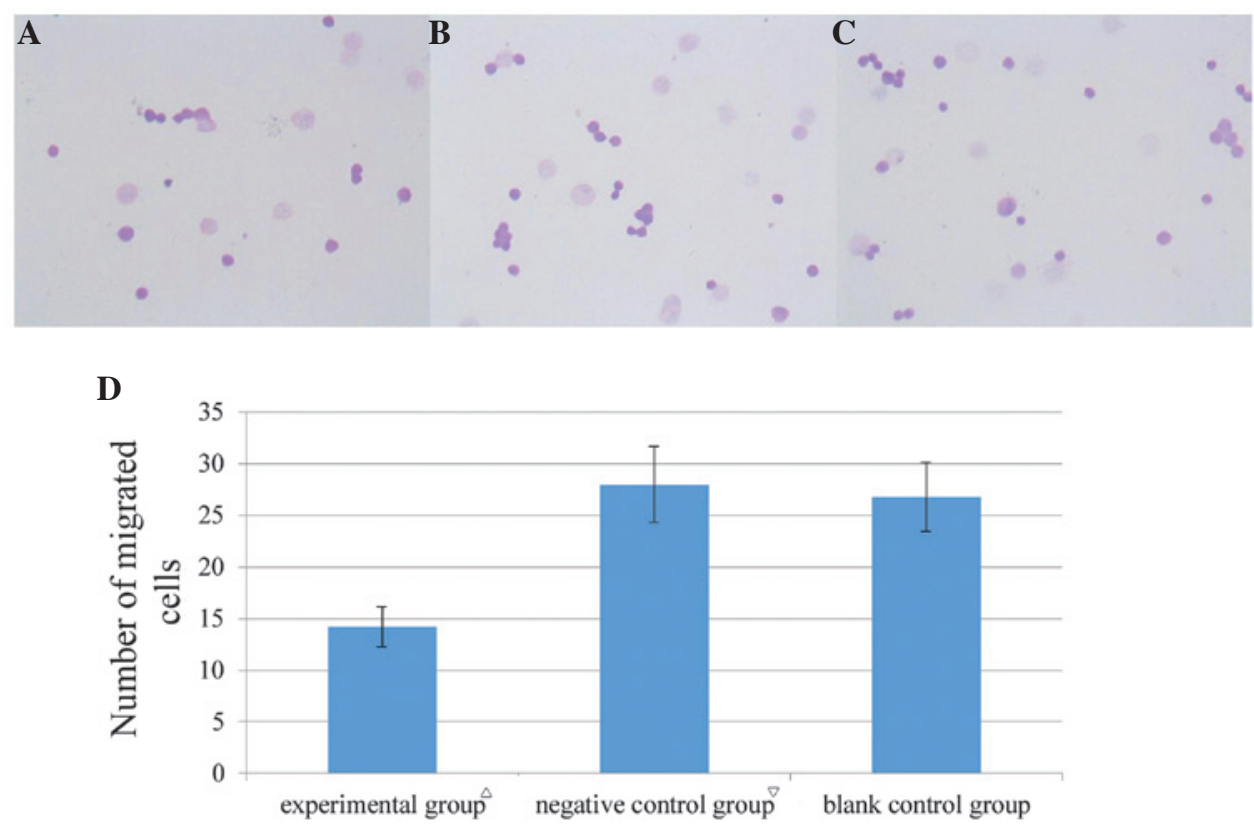

Figure 5. Cell migration activity. HT-29 cells that had migrated to the external surface of the membrane were stained with hematoxylin and eosin. Data represent the mean number of migrating cells in five fields at $x 400$ magnification. (A) Experimental group, (B) negative control group, (C) blank control group; (D) quantification of the number of migrated cells for each group. ${ }^{\Delta} \mathrm{P}<0.05$ vs. the negative control and blank control groups; ${ }^{\nabla} \mathrm{P}>0.05$ vs. the blank control group.

after lentiviral transfection. Survival rates reached their lowest value on the third day, and then began to gradually increase. These data suggested that the lentiviral vector itself was cytotoxic, leading to decreased cell survival.

CXCR7-knockdown inhibits cell migration. Transwell migration assays were performed to evaluate whether CXCR7 plays a role in HT-29 cell migration. Upon CXCR7-knockdown, cell migration significantly decreased compared with the negative control and blank control groups (Fig. 5, P<0.05), but did not significantly change between the two control groups (Fig. 5, $\mathrm{P}>0.05$ ). The results indicated that CXCR7-knockdown inhibited colon cancer cell migration.

\section{Discussion}

The CXCL12-CXCR4 axis has been shown to regulate cancer growth and metastasis $(11,12)$. Increasing evidence has suggested that CXCR7 acts as an alternative CXCL12 receptor and is expressed on embryonic and neoplastic transformed cells, but is absent or weakly expressed in normal tissues $(1,7)$. Studies have also shown that CXCR7 is involved in various biological functions, including cancer cell proliferation, invasion and migration $(13,14)$.

A previous study found that CXCR7 was co-expressed with epidermal growth factor receptor and/or CXCR4 (double- or triple-positive) to contribute to cervical cancer progression (15). Other studies of prostate and hepatocellular carcinomas have shown that CXCR7 promotes vascular endothelial growth factor secretion, resulting in tumor angiogenesis $(16,17)$. The CXCR7 transduction pathway involves $\beta$-arrestin 2 recruitment and enhanced extracellular signal-regulated kinase and p38 signaling in response to CXCL12 stimulation $(8,18)$; however, it does not involve increased K-Ras activity (4).

Although CXCR7 has been widely implicated in various types of cancer, its function in colon cancer remains unclear. We hypothesized that CXCR7 may contribute to colon cancer progression through the promotion of cell survival and migration; therefore, the localization of CXCR7 in human colon cancer cells in vitro and the role of CXCR7 in cell survival and migration were evaluated in the present study.

In this study, it was found that the HT-29 human colon cancer cell line expressed higher CXCR7 levels than SW-480 cells (Fig. 1), and HT-29 cells were therefore used for further analyses. Recombinant CXCR7-siRNA lentivirus was constructed and transfected into HT-29 cells with $\sim 80 \%$ transfection efficiency (Fig. 2). Consistent with several studies that CXCR7 provides a survival advantage for cancer cells $(1,7,16)$, the present data demonstrated that CXCR7-depleted HT-29 cells had significantly decreased CSRs (Table I and Fig. 4), indicating that $\mathrm{CXCR} 7$ facilitates HT-29 cell survival in vitro; however, HT-29 cells transfected with LV-shRNA negative control lentiviral vector also showed a significant reduction in cell survival, suggesting that the lentivirus itself was cytotoxic.

Transwell migration assays revealed that knocking down CXCR7 significantly inhibited cell migration (Fig. 5), suggesting that CXCR7 facilitates cell migration, which may contribute to tumor invasion or metastasis. These data are consistent with those of previous studies, showing that decreased CXCR7 expression in cancer cells resulted in decreased cell migration $(19,20)$.

Since invasion and metastasis are the primary causes of cancer-related morbidity and mortality, small-molecule CXCR7 inhibitors could be highly beneficial cancer therapies. The CXCR7 antagonist CCX771 has been shown to reduce 
extravasation and attenuate metastasis in breast cancer $(9,21)$, providing an attractive therapeutic modality.

Using IF microscopy, it was found in the present study that CXCR7 localized to the cytomembrane; however, the literature describes conflicting results. A study by Berahovich et al (22) did not detect any surface CXCR7 signal in the PC-3 prostate cancer cell line; however, the present results are consistent with the findings of Singh and Lokeshwar (23), which showed that CXCR7 localized to the membrane and did not emit a strong intracellular signal (Fig. 3). Furthermore, CXCR7 membrane expression was detected in all HT-29 colon cancer cells in the present study. Membrane localization of CXCR7 is beneficial for its use as a cancer target.

In conclusion, the present study provides insight into the function of CXCR7 in colon cancer cells. CXCR7-knockdown negatively affected cell survival and migration in vitro, suggesting that CXCR7 functions in tumor aggravation. The present study also supports the previous finding that CXCR7 is expressed on the cytomembrane rather than being found intracellularly, which may be of benefit for the therapeutic targeting of CXCR7. Further research will focus on the molecular mechanisms of CXCR7 in colon cancer and its biological effects in vivo and the development of CXCR7-targeted therapies to improve survival.

\section{Acknowledgements}

The authors would like to acknowledge Professor Hui-Qing Mao for statistical assistance and Xiao-Hua Li for technical assistance. This study was also supported by Professor Guang-Hua Yang from Telebio Biomedical Co., Ltd.

\section{References}

1. Burns JM, Summers BC, Wang Y, Melikian A, Berahovich R, Miao Z, Penfold ME, Sunshine MJ, Littman DR, Kuo CJ, et al: A novel chemokine receptor for SDF-1 and I-TAC involved in cell survival, cell adhesion and tumor development. J Exp Med 203: 2201-2213, 2006.

2. Hartmann TN, Grabovsky V, Pasvolsky R, Shulman Z, Buss EC, Spiegel A, Nagler A, Lapidot T, Thelen M and Alon R: A crosstalk between intracellular CXCR7 and CXCR4 involved in rapid CXCL12-triggered integrin activation but not in chemokine-triggered motility of human T lymphocytes and CD34+ cells. J Leukoc Biol 84: 1130-1140, 2008

3. Levoye A, Balabanian K, Baleux F, Bachelerie F and Lagane B: CXCR7 heterodimerizes with CXCR4 and regulates CXCL12-mediated G protein signaling. Blood 113: 6085-6093, 2009.

4. Heinrich EL, Lee W, Lu J, Lowy AM and Kim J: Chemokine CXCL12 activates dual CXCR4 and CXCR7-mediated signaling pathways in pancreatic cancer cells. J Transl Med 10: 68, 2012.

5. Odemis V, Boosmann K, Heinen A, Küry P and Engele J: CXCR7 is an active component of SDF-1 signalling in astrocytes and Schwann cells. J Cell Sci 123: 1081-1088, 2010.
6. Infantino S, Moepps B and Thelen M: Expression and regulation of the orphan receptor RDC1 and its putative ligand in human dendritic and B cells. J Immunol 176: 2197-2207, 2006.

7. Miao Z, Luker KE, Summers BC, Berahovich R, Bhojani MS, Rehemtulla A, Kleer CG, Essner JJ, Nasevicius A, Luker GD, et al: CXCR7 (RDC1) promotes breast and lung tumor growth in vivo and is expressed on tumor-associated vasculature. Proc Natl Acad Sci USA 104: 15735-15740, 2007.

8. Wang Y, Li G, Stanco A, Long JE, Crawford D, Potter GB, Pleasure SJ, Behrens T and Rubenstein JL: CXCR4 and CXCR7 have distinct functions in regulating interneuron migration. Neuron 69: 61-76, 2011.

9. Zabel BA, Lewén S, Berahovich RD, Jaén JC and Schall TJ: The novel chemokine receptor CXCR7 regulates trans-endothelial migration of cancer cells. Mol Cancer 10: 73, 2011.

10. Wang HX, Chen DJ, Hu G, Cheng W and Yang KY: The effect of lentiviral vector of shRNA on CXCR7 expression in human colon cancer. Zhong Hua Pu Tong Wai Ke Za Zhi 18: 156-161, 2009 (In Chinese)

11. Muller A, Homey B, Soto H, Ge N, Catron D, Buchanan ME, McClanahan T, Murphy E, Yuan W, Wagner SN, et al: Involvement of chemokine receptors in breast cancer metastasis. Nature 410: 50-56, 2001.

12. Vandercappellen J, Van Damme J and Struyf S: The role of CXC chemokines and their receptors in cancer. Cancer Lett 267: 226-244, 2008

13. Hao M, Zheng J, Hou K, Wang J, Chen X, Lu X, Bo J, Xu C, Shen K and Wang J: Role of chemokine receptor CXCR7 in bladder cancer progression. Biochem Pharmacol 84: 204-214, 2012.

14. Yates TJ, Knapp J, Gosalbez M, Lokeshwar SD, Gomez CS, Benitez A, Ekwenna OO, Young EE, Manoharan M and Lokeshwar VB: C-X-C chemokine receptor 7: A functionally associated molecular marker for bladder cancer. Cancer 119: 61-71, 2013.

15. Schrevel M, Karim R, ter Haar NT, van der Burg SH, Trimbos JB, Fleuren GJ, Gorter A and Jordanova ES: CXCR7 expression is associated with disease-free and disease-specific survival in cervical cancer patients. Br J Cancer 106: 1520-1525, 2012.

16. Wang J, Shiozawa Y, Wang J, Wang Y, Jung Y, Pienta KJ, Mehra R, Loberg R and Taichman RS: The role of CXCR7/RDC1 as a chemokine receptor for CXCL12/SDF-1 in prostate cancer. J Biol Chem 283: 4283-4294, 2008.

17. Zheng K, Li HY, Su XL, Wang XY, Tian T, Li F and Ren GS: Chemokine receptor CXCR7 regulates the invasion, angiogenesis and tumor growth of human hepatocellular carcinoma cells. J Exp Clin Cancer Res 29: 31, 2010.

18. Décaillot FM, Kazmi MA, Lin Y, Ray-Saha S, Sakmar TP and Sachdev P: CXCR7/CXCR4 heterodimer constitutively recruits beta-arrestin to enhance cell migration. J Biol Chem 286: 32188-32197, 2011.

19. Choi YH, Burdick MD, Strieter BA, Mehrad B and Strieter RM: CXCR4, but not CXCR7, discriminates metastatic behavior in non-small cell lung cancer cells. Mol Cancer Res 12: 38-47, 2014.

20. Liu L, Zhao X, Zhu X, Zhong Z, Xu R, Wang Z, Cao J and Hou Y: Decreased expression of miR-430 promotes the development of bladder cancer via the upregulation of CXCR7. Mol Med Rep 8: 140-146, 2013.

21. Hawkins $\mathrm{OE}$ and Richmond A: The dynamic yin-yang interaction of CXCR4 and CXCR7 in breast cancer metastasis. Breast Cancer Res 14: 103, 2012.

22. Berahovich RD, Penfold ME and Schall TJ: Nonspecific CXCR7 antibodies. Immunol Lett 133: 112-114, 2010.

23. Singh RK and Lokeshwar BL: The IL-8-regulated chemokine receptor CXCR7 stimulates EGFR signaling to promote prostate cancer growth. Cancer Res 71: 3268-3277, 2011. 